\title{
Generation of recombinant scFv antibody fragments against Ochratoxin A (OTA)
}

\author{
Ranya Pranomphon ${ }^{1}$, Witsanu Srila ${ }^{1}$, and Montarop Yamabhai ${ }^{1, *}$ \\ ${ }^{1}$ School of Biotechnology: Institute of Agricultural Technology, Suranaree University of Technology, 111 University Avenue, Nakhon \\ Ratchasima 30000, Thailand \\ *Corresponding author: montarop@sut.ac.th
}

\begin{abstract}
Ochratoxin A (OTA) is a mycotoxin commonly found in agricultural products and can accumulate in the blood and tissues after contaminated food is consumed. Recombinant single-chain antibody fragments (scFv) against OTA were selected from phage display libraries. After one round of biopanning against BSA-conjugated OTA (OTA-BSA), 52 and 6 phage clones displaying scFv antibodies were isolated from human (Yamo I.3) and rabbit (Bozmix I.2) libraries. Two phage clones (one from each library, i.e. yOTA1e3 and bOTA2a9) showed binding to free toxin by competitive ELISA. The soluble scFv antibodies were produced by superinfecting phage clones into Escherichia coli suppressor strain HB2151. The scFv genes from these two phage clones were sub-cloned into pKP300 $\Delta$ III vectors to generate scFv-AP fusions. The binding affinity $\left(\mathrm{IC}_{50}\right)$ of antibodies derived from the human library were higher than those from the rabbit library. The binding property of recombinant antibodies in the form of scFv-AP was better than those in soluble scFv form. Cross-reactivity analysis indicated that the two recombinant antibodies did not cross-react with other soluble toxins, namely AFB1, DON, ZEN, and FB. The ability to use the recombinant scFv-AP to detect contaminated toxins in an agricultural product (corn) was demonstrated. These antibodies can be used as a template for further engineering and optimization for the detection of contaminated OTAs in the future.
\end{abstract}

KEYWORDS alkaline phosphatase fusion; ochratoxin A; phage display; recombinant antibody; single chain fragments

\section{Introduction}

Ochratoxin A (OTA) is a mycotoxin, produced by fungi such as Aspergillus ochraceous and Penicillium verrucosum (Pfohl-Leszkowicz and Manderville 2007). It is commonly found during the processing and storage of agricultural products (Zinedine and Mañes 2009). OTA has been found in a wide variety of agricultural commodities, including coffee, cereals, dried fruits, and wine (Giraudi et al. 2007). In addition to being nephrotoxic, teratogenic, neurotoxic and immunotoxic, OTA displays carcinogenic and immunosuppressive properties, and has been classified as a Group 2B carcinogen by the International Agency for Research Cancer (Yang et al. 2015; Zou et al. 2016). This toxin is hazardous to both humans and animals and is very harmful because it is stable and can accumulate in the circulatory system, liver and other tissues (Turner et al. 2009; Peraica et al. 2010). Analytical methods such as thin layer chromatography (TLC), high performance liquid chromatography (HPLC) and gas chromatography (GC) (Turner et al. 2009) have been used to control OTA that contaminates both food and feed in agricultural products but these techniques are expensive and time- consuming (Zou et al. 2016). Immunological analysis, especially enzyme-linked immunosorbent assay (ELISA), which uses monoclonal or polyclonal antibodies, has several advantages including high sensitivity, high specificity and higher simplicity compared with instrumental methods (Rangnoi et al. 2011; Qiu et al. 2015). However, the cost for the production of antibodies is still relatively high. Phage display technology, which was established by George P. Smith in 1985 (Smith 1985), is an alternative approach to the generation of recombinant antibodies. This technology uses filamentous bacteriophage, e.g., M13 to displayed antibody fragment, such as single-chain Fragment variable (scFv) on its surface. The key advantage of this technology is the direct linkage between genotypes and phenotypes (Hoogenboom et al. 1998), allowing further engineering or large-scale production of recombinant antibodies from Escherichia coli or other appropriate expression hosts without the use of experimental animals (Better et al. 1988; Pansri et al. 2009). In this study, recombinant antibody fragments (scFv) were selected by biopanning from phage-displayed immunized rabbit and human naïve scFv libraries. Two scFv antibodies against OTA were identified and engineered to cre- 
ate scFv-alkaline phosphatase fusions (scFv-AP). Binding properties of these recombinant antibodies obtained from these two libraries were compared and analyzed.

\section{Materials and methods}

\subsection{Materials}

Yamo I.3, a naïve human scFv library, was constructed in our laboratory from B cells in the plasma of 140 nonimmunized human donors in Northeastern Thailand as previously described (Pansri et al. 2009). KM13 helper phage was obtained with the Tomlinson libraries and was propagated as described in the MRC phage display protocols. Ochratoxin A (OTA) conjugated with BSA (OTA-BSA), OVA (OTA-OVA) and KLH (OTA-KLH), and soluble aflatoxins (AFs) B1, deoxynivalenol (DON), zearalenone (ZEN) and fumonisins (FB) toxins were purchased from Sigma, USA, and Aokin, Germany. E. coli TG1 and HB2151 were obtained from MRC, Cambridge, UK. His prob-HRP was purchased from Sigma. Reference corn material were purchased from Trilogy, USA. All experiments were conducted under the Ethical Principles and Guidelines of Suranaree University of Technology.

\subsection{Construction of rabbit scFv antibody library}

The immunized rabbit scFv antibody library was constructed as previously described (Vu et al. 2017). The spleens from two rabbits (White New Zealand), immunized with OTA-BSA and ZON-BSA, were used. The rabbit immune responses were determined by indirect ELISA, using OTA-BSA as a target. Peripheral blood mononuclear cell (PBMC) was collected from ear vein and total RNA was extracted according to the TRIZOL extraction method. Three $\mu \mathrm{g}$ of total RNA from each rabbit was used as template to generate cDNA, using M-MuLV Reverse Transcriptase. Then, the light and heavy chain $\left(\mathrm{V}_{\mathrm{L}}\right.$ and $V_{H}$ ) genes were amplified with separate sets of 29 PCR primers, using a Taq DNA polymerase. The amplified VH and VL sequences were linked via a polynucleotide linker by pull-through PCR and cloned into phagemids vector (pMOD) between the 5'Sfi I or 3'Not I restriction sites, as previously described (Pansri et al. 2009). This library was designated Bozmix I.2

\subsection{Biopanning}

Biopanning was performed according to Rangnoi et al. (2011) using Yamo I.3 (Pansri et al. 2009) and rabbit Bozmix library, which were constructed as described above. One well of Immuno 96 microWellTM plate (Nunc, Denmark) was coated with $25 \mu \mathrm{g}$ of OTABSA conjugate in PBS buffer and incubated at $4^{\circ} \mathrm{C}$ for overnight. The next day, the well was blocked with PBS supplemented with skimmed milk (2\%, w/v, MPBS) and incubated for $1 \mathrm{~h}$ at room temperature. Following that, the well was washed three times with PBS. The libraries were pre-incubated with $2 \%(\mathrm{w} / \mathrm{v})$ MPBS and $1 \%(\mathrm{w} / \mathrm{v})$
BSA for $30 \mathrm{~min}$ at room temperature before being added into wells of immunized toxin and then incubated at room temperature for $2 \mathrm{~h}$. Then, the well was washed 10 times with PBST (PBS supplemented with $0.05 \%(\mathrm{v} / \mathrm{v})$ Tween 20 ) and with PBS 10 times to remove the unbound phage. Bound phage was eluted by adding $100 \mu \mathrm{L}$ of $1 \mathrm{mg} / \mathrm{mL}$ trypsin buffer (in PBS) and incubated at room temperature for 10 min with rotation. Acid elution was subsequently performed by adding $100 \mu \mathrm{L}$ of $100 \mathrm{mM}$ glycine$\mathrm{HCl}, \mathrm{pH} 2.0$ and incubated for $10 \mathrm{~min}$, followed by neutralization with $100 \mu \mathrm{L}$ of neutralization buffer $(200 \mathrm{mM}$ $\mathrm{NaHPO}_{4}, \mathrm{pH}$ 7.5). To isolate individual phage clones, the $\log$ phase $E$. coli TG1 cells were infected with the eluted phage by adding $2 \mathrm{~mL}$ of $E$. coli TG1 log phase with 150 $\mu \mathrm{L}$ eluted phage and incubated at $37^{\circ} \mathrm{C}$ for 30 min without shaking. Follow this, 10 -fold serial dilutions of infected cells were performed using 2xYT media and the cells were spread onto 2xYT agar containing $100 \mu \mathrm{g} / \mathrm{mL}$ ampicillin and $1 \% \mathrm{w} / \mathrm{v}$ glucose. The plates were then incubated at $37^{\circ} \mathrm{C}$ overnight.

\subsection{Individual phage rescue}

Individual phage clones were picked into $100 \mu \mathrm{L}$ of $2 \mathrm{xYT}$ supplemented $100 \mu \mathrm{g} / \mathrm{mL}$ ampicillin and $1 \%(\mathrm{w} / \mathrm{v})$ glucose in each well of a 96-well plate (Nunc, Denmark), and incubated overnight at $37^{\circ} \mathrm{C}$ with shaking. After that, 10 $\mu \mathrm{L}$ from each well were transferred to a new deep-well microculture plate (Nunc, Denmark), containing $400 \mu \mathrm{L}$ of 2xYT plus $100 \mu \mathrm{g} / \mathrm{mL}$ ampicillin and 1\% (w/v) glucose. The first plate was kept as the glycerol stock by adding glycerol to a final concentration of $15 \%$ (v/v) and kept at $-70^{\circ} \mathrm{C}$. The deep-well micro culture plate was then incubated at $37^{\circ} \mathrm{C}$ for $3 \mathrm{~h}$ with vigorous shaking. After that, phage was rescued by adding $10^{10}$ of helper phage to each well and incubated at $37^{\circ} \mathrm{C}$ for $1 \mathrm{~h}$ without shaking. The pellet was collected by spinning at 3,000xg for $15 \mathrm{~min}$, and re-suspended in $400 \mu \mathrm{L}$ of $2 x Y T$ containing $100 \mu \mathrm{g} / \mathrm{mL}$ of ampicillin and $50 \mu \mathrm{g} / \mathrm{mL}$ of kanamycin. After incubation with shaking at $30^{\circ} \mathrm{C}$ for $20 \mathrm{~h}$, the supernatant was collected for phage ELISA after centrifugation at 4,000 rpm for $10 \mathrm{~min}$.

\subsection{Phage ELISA}

The 96-well microtiter plates (Immuno 96 microWell $^{\mathrm{TM}}$, Nunc, Denmark) were immobilized with $2 \mu$ g of OTABSA in PBS buffer, or $1 \%(\mathrm{w} / \mathrm{v})$ bovine serum albumin (BSA) in $100 \mu \mathrm{L}$ PBS (negative control). After incubation at $4^{\circ} \mathrm{C}$ overnight, the wells were blocked with $2 \%$ $(\mathrm{w} / \mathrm{v})$ MPBS for $1 \mathrm{~h}$ at room temperature. The wells were then washed three times with PBS. Then, fifty $\mu \mathrm{L}$ of PBST and $100 \mu \mathrm{L}$ of phage supernatant were added to the plate and incubated at room temperature for $2 \mathrm{~h}$. The unbound phage was washed off 3 times with PBST, followed by 2 times with PBS. Subsequently, $100 \mu \mathrm{L}$ of HRP-labeled anti-M13 (1:5000 dilution in PBS) was added into each well. After $1 \mathrm{~h}$ of incubation at room temperature, the 
wells were washed again, as described above. Then 200 $\mu \mathrm{L}$ of HRP substrate (ABTS, Sigma) were added to each well. After 30 min of incubation at room temperature, the optical density (OD) at $405 \mathrm{~nm}$ was measured using a microtiter plate reader (Tecan, Austria).

\subsection{Expression and Purification of soluble scFv}

\subsubsection{Expression using E. coli HB2151}

The expression of soluble scFv antibody was performed as previously described (Rangnoi et al. 2011). Approximately $10-20 \mu \mathrm{L}$ of phage particles were mixed with $500 \mu \mathrm{L}$ of log-phase $\left(\mathrm{OD}_{600}=0.4\right)$ E. coli HB2151 (nonsuppressor host), and incubated at $37^{\circ} \mathrm{C}$ for $30 \mathrm{~min}$ without shaking. Infected bacteria were then streaked onto 2xYT agar containing $100 \mu \mathrm{g} / \mathrm{mL}$ ampicillin and $1 \%$ (w/v) glucose. After that, the plates were incubated at $37^{\circ} \mathrm{C}$ overnight. A single colony was picked and cultured in $5 \mathrm{~mL}$ of $2 \mathrm{xYT}$ plus $100 \mu \mathrm{g} / \mathrm{mL}$ ampicillin and 2\% (w/v) glucose, and incubated at $30^{\circ} \mathrm{C}$ with vigorous shaking overnight. Fifty $\mu \mathrm{L}$ of overnight culture was added into $5 \mathrm{~mL}$ of $2 \mathrm{xYT}$ containing $100 \mu \mathrm{g} / \mathrm{mL}$ ampicillin and $0.1 \%$ (w/v) glucose, and incubated with shaking at $30^{\circ} \mathrm{C}$ until the $\mathrm{OD}_{600}$ reached 0.9 . Then, $1 \mathrm{mM}$ of isopropylthiogalactoside (IPTG) was added to induce the scFv expression. The incubation was continued at $30^{\circ} \mathrm{C}$ for $20 \mathrm{~h}$. The secreted antibody could be found in the supernatant.

\subsubsection{Expression using E. coli HMS174}

For large-scale expression, the scFv genes of clones Y1E3 and RB2A9 were sub-cloned into pET27b vectors between Nco I and Not I restriction enzymes. The plasmids were purified using commercial kit (QIAgen spin Mini-prepkit, USA) and transformed into E. coli HMS174 pLysS (Novagen). The transformed bacteria were grown in $5 \mathrm{~mL}$ of M9ZB media [Dissolve $10 \mathrm{~g}$ Bacto tryptone, 5 g NaCl, $6 \mathrm{~g} \mathrm{Na}_{2} \mathrm{HPO}_{4}, 3 \mathrm{~g} \mathrm{KH}_{2} \mathrm{PO}_{4}$ and $1 \mathrm{~g} \mathrm{NH}_{4} \mathrm{Cl}$ in 1 liter of water, after autoclaving add $20 \mathrm{ml}$ sterile $20 \%$ glucose and $1 \mathrm{ml}$ sterile $1 \mathrm{M}$ MgS04] (Kunze et al., 1995), containing $50 \mu \mathrm{g} / \mathrm{mL}$ kanamycin and 20\% w/v glucose. The culture was incubated at $30^{\circ} \mathrm{C}, 250 \mathrm{rpm}$ for overnight. Then, $1 \%(\mathrm{v} / \mathrm{v})$ of each overnight culture was added into M9ZB media supplemented with $20 \% \mathrm{w} / \mathrm{v}$ glucose and $50 \mu \mathrm{g} / \mathrm{mL}$ kanamycin. The culture was then incubated with shaking at $30^{\circ} \mathrm{C}$ for $4 \mathrm{~h}$. Later, the cells were centrifuged at $16^{\circ} \mathrm{C}$, $5000 \mathrm{rpm}$ for $15 \mathrm{~min}$ and re-suspended with M9ZB media containing 10\% w/v glycerol, $50 \mu \mathrm{g} / \mathrm{mL}$ kanamycin and $1 \mathrm{mM}$ IPTG (Amresco, USA). The incubation was continued at $16^{\circ} \mathrm{C}, 250 \mathrm{rpm}$ for $20 \mathrm{~h}$, then the cell pellet was collected by centrifugation at $4^{\circ} \mathrm{C}, 8000 \mathrm{rpm}$ for $10 \mathrm{~min}$. Periplasmic extraction was performed to collect scFv antibodies as previously described (Yamabhai et al. 2008). Briefly, $50 \mathrm{~mL}$ of cell culture were spun down to collect the cell. The bacterial cells were then re-suspended in $2.5 \mathrm{~mL}$ of cold spheroplast buffer [1M Tris- $\mathrm{HCl}, \mathrm{pH}$ 8.0, 0.5M EDTA, 20\% sucrose, containing 0.1 M phenylmethylsulfonyl fluoride (PMSF)] and incubated for 5 min on ice. Then, the cells were centrifuged at $8000 \times \mathrm{g}$ for 10 min at $4{ }^{\circ} \mathrm{C}$, and re-suspended in $1.0 \mathrm{~mL}$ of ice-cold sterile water containing $1 \mathrm{mM} \mathrm{MgCl} 2$ and incubated on ice with frequent shaking for $5 \mathrm{~min}$. Periplasmic fractions were collected by centrifugation at $8000 \times \mathrm{g}$ for $15 \mathrm{~min}$ at $4^{\circ} \mathrm{C}$. The extracted scFv antibodies were detected by sodium dodecyl sulphate polyacrylamide gel electrophoresis (SDSPAGE).

\subsection{ScFv ELISA}

The scFv ELISA was similar to the phage ELISA method as describe above except that $50 \mu \mathrm{L}$ of supernatant containing scFv antibody and $50 \mu \mathrm{L}$ of PBST were added into each well instead. The bound scFv was detected by addition of $100 \mu \mathrm{L}$ of His prob-HRP (1:5000 dilution in PBS), using ABTS as substrate. The average optical density (OD) at $405 \mathrm{~nm}$ with standard deviation of triplicate wells was reported.

\subsection{Cloning, expression, and purification of scFv-AP fusion}

The scFv-AP was constructed as previously described (Rangnoi et al. 2011). Briefly, the scFv gene from the phagemid vector was digested with Nco I and Not I restriction enzymes and sub-cloned into pKP300 $\Delta \mathrm{III}$, an alkaline phosphatase fusion vector (Kay and Hoess 1996). The integrity of these constructs were performed by automated DNA sequencing (Macrogen, Korea). To express the scFvalkaline phosphatase (scFv-AP) fusions the recombinant plasmids (pKP300 $\Delta \mathrm{III}$ vector) were extracted and transformed into E. coli TG1 competent cells. A single colony was picked and cultured in $5 \mathrm{~mL}$ of LB (Luria-Bertani) medium containing $100 \mathrm{mg} / \mathrm{mL}$ ampicillin at $37^{\circ} \mathrm{C}$ with shaking at $250 \mathrm{rpm}$, overnight. After that, $100 \mu \mathrm{L}$ of overnight culture was inoculated into $100 \mathrm{~mL}$ of low-phos media [3.75 g ammonium sulphate, $0.71 \mathrm{~g}$ sodium citrate dehydrate, $1.07 \mathrm{~g} \mathrm{KCl}, 5.36 \mathrm{~g}$ Yeast extract, $5.36 \mathrm{~g} \mathrm{Hy-}$

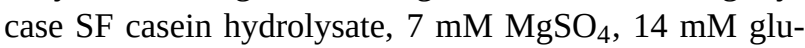
cose per liter, $\mathrm{pH} 7.3$ (adjusted with $\mathrm{KOH}$ ) containing 100 $\mathrm{mg} / \mathrm{mL}$ ampicillin, $1 \mathrm{M} \mathrm{MgSO}_{4}$ and $1 \mathrm{M}$ glucose]. The culture was incubated at $30^{\circ} \mathrm{C}$ with shaking at $250 \mathrm{rpm}$ for $20 \mathrm{~h}$. Then, the cultures were centrifuged at 8,000 rpm for $10 \mathrm{~min}$ at $4^{\circ} \mathrm{C}$. The cell pellets were re-suspended in $10 \mathrm{~mL}$ of fresh lysis buffer (10 mM imidazole ( $\mathrm{pH}$ 8.0), BugBuster 10X, 100 mM PMSF). The cell debris was removed using centrifugation at $8,000 \mathrm{rpm}$ for $15 \mathrm{~min}$ at $4^{\circ} \mathrm{C}$. The recombinant proteins were purified using a Ni-NTA resin, according to the manufacturer's instructions. Subsequently, the eluted proteins were dialyzed with TBS by Amicon Ultra-15 filter device (MW cutoff at $10 \mathrm{kDa}$, Millipore), then $\mathrm{MgCl}_{2}$ was added to the purified protein to a final concentration of $1 \mathrm{mM}$.

\subsection{ScFv-AP ELISA}

The scFv-AP ELISA was performed as previously described (Rangnoi et al. 2011). Briefly, triplicate wells of 
microtiter plate (Immuno 96 Wells $^{\mathrm{TM}}$, Nunc, Denmark) were immobilized with $2 \mu \mathrm{g}$ of OTA-BSA in $100 \mu \mathrm{L}$ PBS or $1 \%(\mathrm{w} / \mathrm{v}) \mathrm{BSA}$ in PBS (a negative control). The plate was kept at $4^{\circ} \mathrm{C}$ overnight. The next day, the plate was blocked with $2 \%(\mathrm{w} / \mathrm{v})$ fat-free powdered milk (MPBS) in TBS. After incubation for $1 \mathrm{~h}$ at room temperature, the wells were washed 3 times with TBST. Then $50 \mu \mathrm{L}$ of TBST and $50 \mu \mathrm{L}$ of scFv-AP fusion was added into each well and incubated at room temperature for 1-2 h. After that, the plate was washed three times with $0.05 \%(\mathrm{v} / \mathrm{v})$ Tween 20 (TBST) and two times with TBS. Finally, 200 $\mu \mathrm{L}$ of p-Nitrophenyl phosphate substrate (pNPP; SIGMA, USA) was added to each well, and the optical density (OD) at $405 \mathrm{~nm}$ was measured after $30 \mathrm{~min}$ of incubation at room temperature.

\subsection{Competitive ELISA}

The wells of 96 -well microtiter plate were coated with $2 \mu \mathrm{g}$ of OTA-BSA. The optimal amount of antibody was first determined by serial dilution ELISA and the amount of the antibody that showed the binding at the log-phase of the binding curve was used. The appropriate concentration of antibody was pre-incubated with varying concentrations of soluble OTA in TBS containing $0.05 \%$ Tween 20 in the wells of the micro-titer plates at $37^{\circ} \mathrm{C}$ for 30 min with shaking at $300 \mathrm{rpm}$. After that, the mixture was transferred into wells of the ELISA plate that had been coated and blocked as described previously. After incubation for $1 \mathrm{~h}$, non-specific adsorption was washed away 3 times with TBS containing $0.05 \%$ Tween 20 , followed by 2 times with TBS. After that, $200 \mu \mathrm{L}$ of substrate solution (pNPP, Sigma, USA) was added into each well. The OD at $405 \mathrm{~nm}$ of triplicate wells was measure using microtiter plate reader (Tecan, Austria).

\subsection{DNA sequence analysis}

The phage clones that showed positive binding by competitive ELISA were collected and the plasmids was prepared using plasmid miniprep kit (Qiagen), and then the DNA sequences were determined by automated DNA sequencing (Macrogen, Korea). The DNA sequences were analyzed with IgBLAST and the complementarity determining regions (CDRs) were identified using Imgt software. The 3D structures were predicted by Phyre2 software.

\subsection{Cross-reactivity analysis}

Cross-reactivity of the isolated antibody against ochratoxin A (OTA), aflatoxin B1 (AFB1), deoxynivalenol (DON), zearalenone (ZEN) and fumonisins (FB) toxins, was evaluated by competitive ELISA, using scFv-AP antibody format. The toxins were pre-incubated with appropriate concentration of antibody at $37^{\circ} \mathrm{C}$ for $30 \mathrm{~min}$, with shaking at $450 \mathrm{rpm}$. Then, the plate was washed 5 times with TBS containing $0.05 \%$ Tween 20 . The OD values were obtained as described above.

\subsection{Spike analysis of OTA in corn sample}

Three gram of toxin-free reference corn material (Trilogy, USA) was added into $15 \mathrm{~mL}$ of $70 \%$ methanol. The extract was shaken for $3 \mathrm{~min}$ at room temperature and left to stand for $10 \mathrm{~min}$ to collect the clear solution. Then the extract was filtered through Whatman filter paper No.1. The spiked solutions with known amounts of OTA (10 $30,000 \mathrm{ng} / \mathrm{mL}$ ) were prepared by adding various concentrations of OTA standards to the extraction solution. After that the spiked solutions were diluted $1: 3$ with $0.05 \%$ (v/v) Tween 20 (TBST). The diluted solution was added into plate instead of OTA standard by competitive ELISA as described before. Data were collected to plot the curve between A/A0 and concentration of spiked OTA. Limit of detection (LOD) and $\mathrm{IC}_{50}$ was evaluated from the graph.

\section{Results and discussion}

After one round of biopanning using OTA-BSA as a target, 52 clones from human library (Yamo I.3) and 6 clones from rabbit library (Bozmix I.2) were obtained. Amino acid sequence analysis indicated that only 2 unique sequences, one from human and one from rabbit libraries, were affinity selected. These two clones were designated RB2A9 and Y1E3, for scFv derived from phage displayedrabbit, and human libraries, respectively. The reason why we only obtained 2 unique clones could be because the sizes of the two libraries were relatively small and these were the clones that could grow very well. The nucleotide sequences of clone RB2A9 from rabbit library and clone Y1E3 from human library were translated into

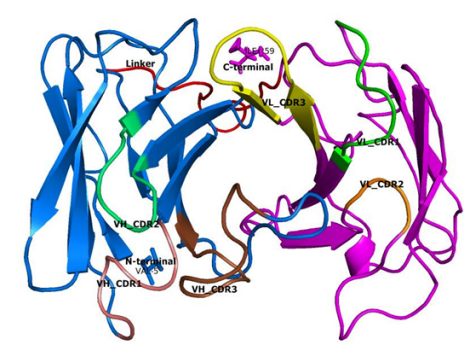

(a)

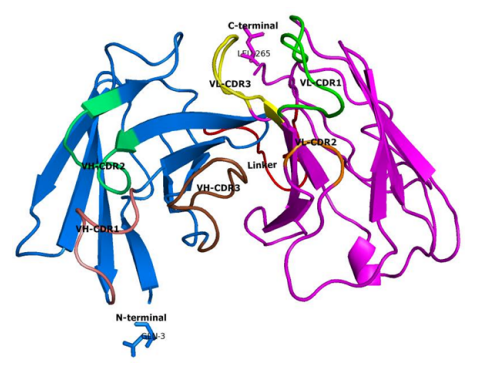

(b)

FIGURE 1 Three dimensional structure prediction of scFv-AP clone RB2A9 (a) and clone Y1E3 (b). The $V_{H}$ and $V_{L}$ are shown in blue and purple, respectively. The complementarity-determining region (CDR) of $\mathrm{V}_{\mathrm{H}}$ and $\mathrm{V}_{\mathrm{L}}, \mathrm{N}$-terminus, and $\mathrm{C}$-terminus are indicated. 


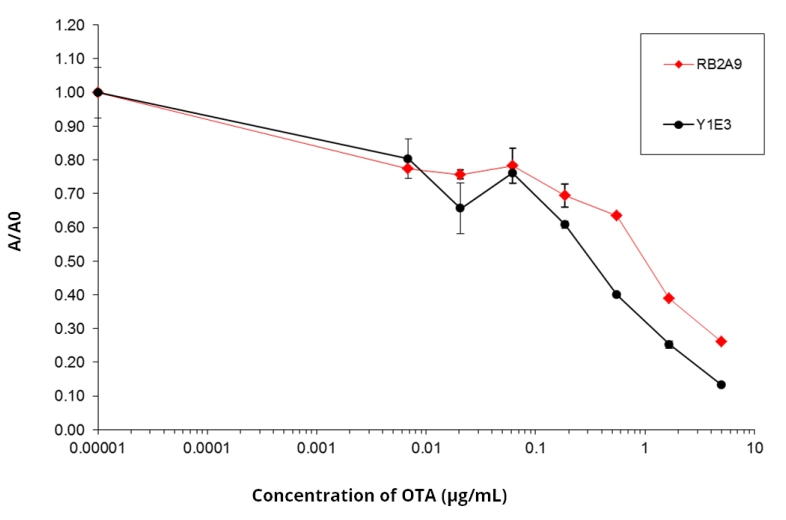

FIGURE 2 Competitive ELISA analysis of scFv clone RB2A9 from rabbit and clone Y1E3 from human against OTA. The results are shown as $A / A 0$, where $A$ is the absorbance of antibody in the presence of varying OTA concentration, and $A 0$ is the absorbance of antibody in the absence of soluble OTA.

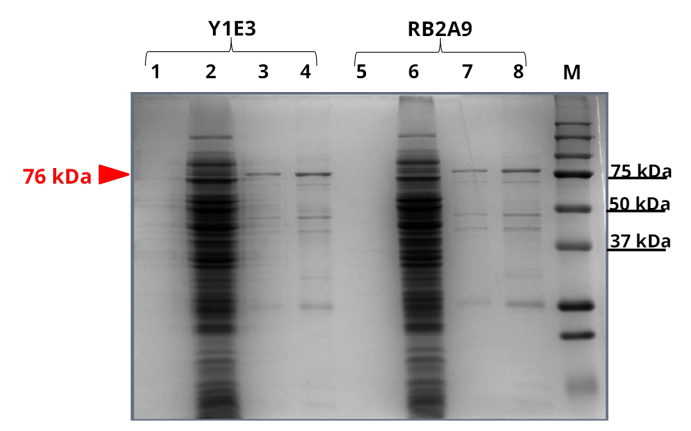

FIGURE 3 SDS-PAGE of purified scFv-AP clone Y1E3 (human) and clone RB2A9 (Rabbit) in E. coli TG1. Lane 1 and 5, culture supernatants; lane 2 and 6, crude extract of cell lysate; lane 3 and 7, purified scFv antibody; lane 4 and 8 , purified and concentrated scFv antibody. M: kaleidoscope protein standard (Bio-Rad). The scFvAP band of approximately $76 \mathrm{kDa}$ is indicated.

amino acid sequences, and the schematic ribbon cartoon of scFv clone RB2A9 and Y1E3 were shown in Figure 1. The complementarity-determining region (CDR1, CDR2 and CDR3) of the $\mathrm{V}_{\mathrm{H}}$ and $\mathrm{V}_{\mathrm{L}}$ were indicated by pymol program. To express soluble scFv antibody formats, the scFv genes were sub-cloned into pET27b vector and expressed in E. coli HMS174, pLysS BL21. After that, competitive ELISA was performed to detect the binding ability between soluble scFv and free OTA (Figure 2). The results indicated that scFv clone Y1E3 from human library could bind to the target better than the clone RB2A9 from rabbit library. The $\mathrm{IC}_{50}$ of clone RB2A9 and Y1E3 were 1.0 $\mu \mathrm{g} / \mathrm{mL}$ and $0.3 \mu \mathrm{g} / \mathrm{mL}$, respectively. Previous study has shown that rabbit $\mathrm{scFv}$ was relatively difficult to express in E. coli (Ayyar et al. 2015), therefore the rabbit clone that could bind better to OTA might have been selected out because it could not be expressed in E. coli.

Since we have previously shown that the recombinant antibody in the form of scFv-AP format is more efficient to be used as one-step detection probe for the detection of mycotoxin contaminations (Rangnoi et al. 2011), in

\section{Y1E3 RB2A9}

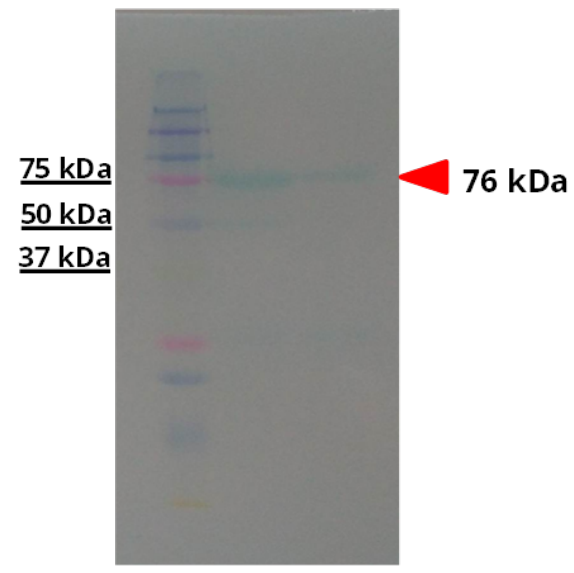

FIGURE 4 Western blot analysis of purified scFv-AP clone Y1E3 (human) and clone RB2A9 (rabbit). M: kaleidoscope protein standard (Bio-Rad). The scFv-AP band of approximately $76 \mathrm{kDa}$ is indicated.

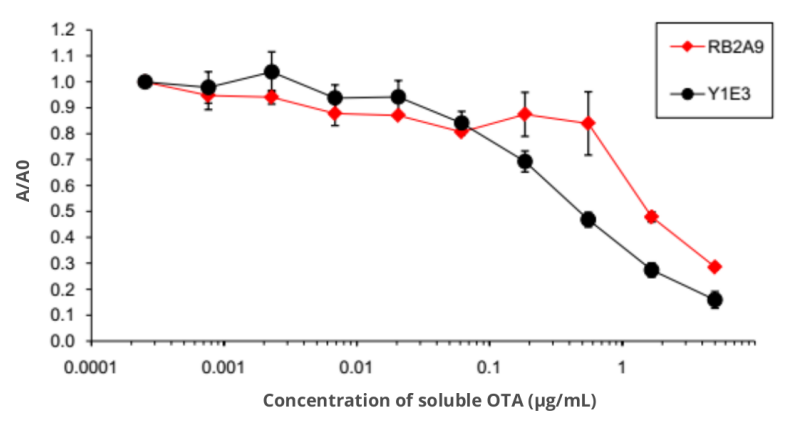

FIGURE 5 Competitive ELISA of scFv-AP clone RB2A9 from rabbit and clone Y1E3 from human. The results are shown as A/AO, where $A$ is the absorbance of antibody in presence of varying concentration of OTA, and AO is the absorbance of antibody in the absence of soluble OTA.

the next step, the scFv-alkaline phosphatase (scFv-AP) fusions were generated by insertion of the $\mathrm{scFv}$ gene into recombinant plasmid (pKP300 $\Delta \mathrm{III}$ vector) (Pershad et al. 2011). After that, the recombinant scFv-AP fusions were purified from cell lysate by immobilized metal affinity chromatography (IMAC) using Ni-NTA resin. The purified fractions were detected by SDS-PAGE (Figure 3) and western blot analysis (Figure 4). The expected size of scFv-AP fusion was about $76 \mathrm{kDa}$. The reason why the protein could not be purified to apparent homogeneity could be because the His-tag was not very efficient for protein purification (Berkman, M., personal communication). After that, competitive ELISA was performed by one-step detection procedure to evaluate the binding of scFv-AP antibody to soluble OTA (Figure 4). The result indicated that the IC 50 of clone RB2A9-AP and Y1E3AP were $1.6 \mu \mathrm{g} / \mathrm{mL}$ and $0.49 \mu \mathrm{g} / \mathrm{mL}$, respectively. These results confirmed previous observation that scFv derived from human library bound better to the free toxin and that the antibody in the scFv-AP fusion format has better binding sensitivity than that of the free $\mathrm{scFv}$ format. 


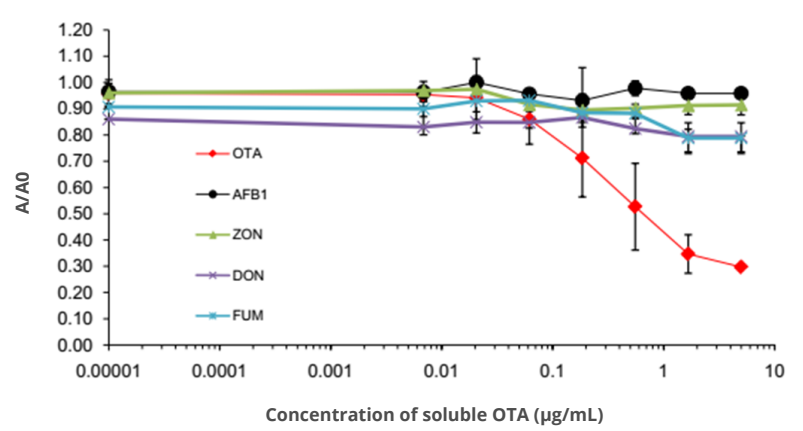

(a)

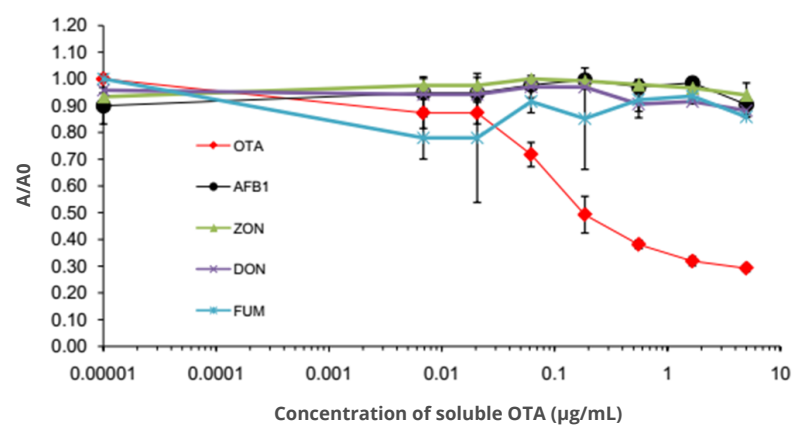

(b)

FIGURE 6 Cross-reactivity assay. Competitive ELISA of scFv-AP clone RB2A9 from rabbit (a) and clone Y1E3 from human (b) with different common mycotoxins are shown.

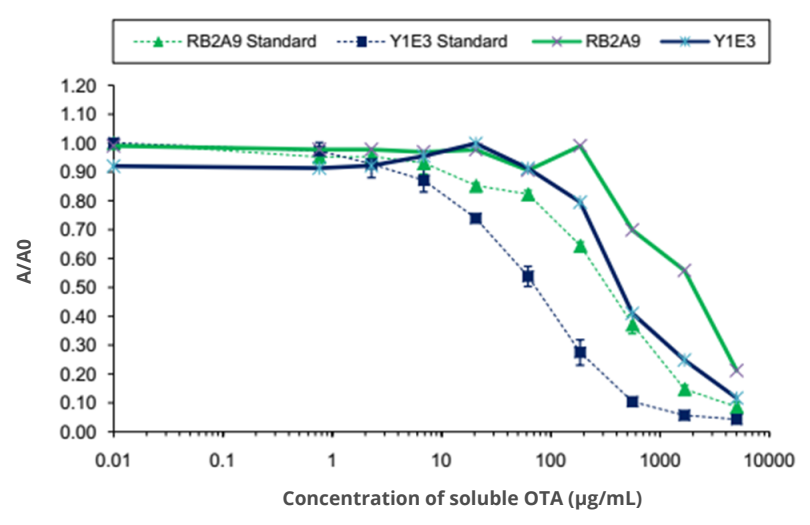

FIGURE 7 Spike analysis. Various concentration of OTA were spiked on corn sample extract and tested against scFv-AP clone RB2A9 from rabbit, and clone Y1E3 from human. The inhibition curved are compared with the standard curves (dashed lines).

In the next step, cross-reactivity analysis of scFv-AP clone RB2A9 and Y1E3 were performed with various soluble mycotoxins; namely, ochratoxin A (OTA), aflatoxins B1 (AFB1), deoxynivalenol (DON), zearalenone (ZEN), and fumonisins (FB), by competitive ELISA (Figure 5). The results showed that both of the ScFv-AP clones did not cross-react with the other tested mycotoxins, indicating that specific ScFv-AP antibodies against OTA could be generated.

Finally, to demonstrate the potential application of scFv-AP for the detection of mycotoxins from agricultural samples, the spike analysis of OTA was performed. Reference corn material containing no toxin (Trilogy, USA) was extracted and spiked with various concentration of OTA before subjecting to competitive ELISA (Figure 6). The result indicated that the limit of detection (LOD) of scFv-AP clones RB2A9 and Y1E3 were $400 \mathrm{ng} / \mathrm{mL}$ and $200 \mathrm{ng} / \mathrm{mL}$, respectively. The detection limit was much higher than the values obtained from competitive ELISA using standard OTA.

These results indicated that the corn matrix could interfere with the binding of scFv-AP to OTA, using the extraction method as described in this work. Therefore, further optimizations of various factors are required before recombinant scFv-AP antibody can be adapted for OTA detection in the field. These include 1) enhancing of affinity of scFv-AP, 2) optimizing competitive ELISA assay, and 3) optimizing sample extraction procedure to fit different agricultural products.

\section{Conclusions}

In this study, OTA-specific scFv antibodies were generated from rabbit and human phage display antibody library. Potential application of scFv-AP format as one-step detection probe for the detection of free OTA was demonstrated.

\section{Acknowledgments}

This work was supported by Grants from Suranaree University of Technology (SUT) and Agricultural Research Development (Public Organization) [ARDA] grants No. CRP550701085. RP was supported by the Royal Golden Jubilee scholarship from Thailand Research Fund (TRF).

\section{Authors' contributions}

RP performed most of the experiment and draft the manuscript. WS constructed the phage display library, supervised laboratory work and drafted the manuscript. MY conceived of the study and edited the manuscript. All authors read and approved the final version of the manuscript.

\section{Competing interests}

MY is on the editorial board of the Indonesian Journal of Biotechnology, and was recused from this article's review and decision. The authors declare no other competing interests.

\section{References}

Ayyar BV, Hearty S, O’Kennedy R. 2015. Facile domain rearrangement abrogates expression recalcitrance in a rabbit scFv. Appl Microbiol Biotechnol. 99(6):26932703. doi:10.1007/s00253-014-6268-4.

Better M, Chang CP, Robinson RR, Horwitz AH. 1988. Escherichia coli secretion of an active chimeric antibody fragment. Science 240(4855):1041-1043. doi:10.1126/science.3285471. 
Giraudi G, Anfossi L, Baggiani C, Giovannoli C, Tozzi C. 2007. Solid-phase extraction of ochratoxin A from wine based on a binding hexapeptide prepared by combinatorial synthesis. J Chromatogr A 1175(2):174180. doi:10.1016/j.chroma.2007.10.057.

Hoogenboom HR, de Bruïne AP, Hufton SE, Hoet RM, Arends JW, Roovers RC. 1998. Antibody phage display technology and its applications. Immunotechnology 4(1):1-20. doi:10.1016/S1380-2933(98)00007-4.

Kay BK, Hoess RH. 1996. Principles and applications of phage display. In: Phage display of peptides and proteins. Burlington: Academic Press. p. 21-34. doi:10.1016/B978-012402380-2/50004-6.

Pansri P, Jaruseranee N, Rangnoi K, Kristensen P, Yamabhai M. 2009. A compact phage display human scFv library for selection of antibodies to a wide variety of antigens. BMC Biotechnol. 9(1):6. doi:10.1186/14726750-9-6.

Peraica M, Flajs D, Domijan AM, Ivić D, Cvjetković B. 2010. Ochratoxin A contamination of food from Croatia. Toxins 2(8):2098-2105. doi:10.3390/toxins2082098.

Pershad K, Sullivan MA, Kay BK. 2011. Drop-out phagemid vector for switching from phage displayed affinity reagents to expression formats. Anal Biochem. 412(2):210-216. doi:10.1016/j.ab.2011.02.006.

Pfohl-Leszkowicz A, Manderville RA. 2007. Ochratoxin A: an overview on toxicity and carcinogenicity in animals and humans. Mol Nutr Food Res. 51(1):61-99. doi:10.1002/mnfr.200600137.

Qiu YL, He QH, Xu Y, Bhunia AK, Tu Z, Chen B, Liu YY. 2015. Deoxynivalenol-mimic nanobody isolated from a naïve phage display nanobody library and its application in immunoassay. Anal Chim Acta 887:201-208. doi:10.1016/j.aca.2015.06.033.

Rangnoi K, Jaruseranee N, O’Kennedy R, Pansri P, Yamabhai M. 2011. One-step detection of aflatoxin-b1 using scFv-alkaline phosphatase-fusion selected from human phage display antibody library. Mol Biotechnol. 49(3):240-249. doi:10.1007/s12033-011-9398-2.

Smith GP. 1985. Filamentous fusion phage: novel expression vectors that display cloned antigens on the virion surface. Science 228(4705):1315-1317. doi:10.1126/science.4001944.

Turner NW, Subrahmanyam S, Piletsky SA. 2009. Analytical methods for determination of mycotoxins: a review. Anal Chim Acta 632(2):168-180. doi:10.1016/j.aca.2008.11.010.

Vu NX, Pruksametanan N, Srila W, Yuttavanichakul W, Teamtisong K, Teaumroong N, Boonkerd N, Tittabutr P, Yamabhai M. 2017. Generation of a rabbit single-chain fragment variable ( $\mathrm{scFv}$ ) antibody for specific detection of Bradyrhizobium sp. DOA9 in both free-living and bacteroid forms. PLoS One 12(6):e0179983. doi:10.1371/journal.pone.0179983.
Yamabhai M, Emrat S, Sukasem S, Pesatcha P, Jaruseranee N, Buranabanyat B. 2008. Secretion of recombinant Bacillus hydrolytic enzymes using Escherichia coli expression systems. J Biotechnol. 133(1):50-57. doi:10.1016/j.jbiotec.2007.09.005.

Yang L, Zhang Y, Li R, Lin C, Guo L, Qiu B, Lin Z, Chen G. 2015. Electrochemiluminescence biosensor for ultrasensitive determination of ochratoxin A in corn samples based on aptamer and hyperbranched rolling circle amplification. Biosens Bioelectron. 70:268274. doi:10.1016/j.bios.2015.03.067.

Zinedine A, Mañes J. 2009. Occurrence and legislation of mycotoxins in food and feed from Morocco. Food Control 20(4):334-344. doi:10.1016/j.foodcont.2008.07.002.

Zou X, Chen C, Huang X, Chen X, Wang L, Xiong Y. 2016. Phage-free peptide ELISA for ochratoxin A detection based on biotinylated mimotope as a competing antigen. Talanta 146:394-400. doi:10.1016/j.talanta.2015.08.049. 